\title{
Surgical Outcome of Adult Idiopathic Chiari Malformation Type 1
}

\author{
Woon Tak Yuh, M.D., ${ }^{1}$ Chi Heon Kim, M.D., Ph.D., ${ }^{1,2,3,4}$ Chun Kee Chung, M.D., Ph.D., ${ }^{1,2,3,4,5}$ Hyun-Jib Kim, M.D., Ph.D., ${ }^{2,6}$ \\ Tae-Ahn Jahng, M.D., Ph.D., ${ }^{2,6}$ Sung Bae Park, M.D. ${ }^{2,7}$ \\ ${ }^{1}$ Department of Neurosurgery, Seoul National University Hospital, Seoul, Korea \\ ${ }^{2}$ Department of Neurosurgery, Seoul National University College of Medicine, Seoul, Korea \\ ${ }^{3}$ Neuroscience Research Institute, Seoul National University Medical Research Center, Seoul, Korea \\ ${ }^{4}$ Clinical Research Institute, Seoul National University Hospital, Seoul, Korea \\ ${ }^{5}$ Department of Brain and Cognitive Sciences, Seoul National University College of Natural Sciences, Seoul, Korea \\ ${ }^{6}$ Department of Neurosurgery, Seoul National University Bundang Hospital, Seongnam, Korea \\ ${ }^{7}$ Department of Neurosurgery, Seoul National University Boramae Hospital, Seoul, Korea
}

Objective : The pathophysiology of idiopathic Chiari malformation (CM) type 1 is disturbance of free cerebrospinal fluid (CSF) flow and restoration of normal CSF flow is the mainstay of treatment. Additional migration of the medulla oblongata in pediatric patients is referred to as CM type 1.5, but its significance in adult patients is unknown. This study is to compare surgical outcomes of adult idiopathic CM type 1.5 with that of type 1.

Methods : Thirty-eight consecutive adult patients ( $\mathrm{M}: \mathrm{F}=11: 27$; median, 33.5; range, 18-63) with syringomyelia due to idiopathic $\mathrm{CM}$ type 1 were reviewed. Migration of the medulla oblongata was noted in 13 patients. The modified McCormick scale (MMS) was used to evaluate functional status before and one year after surgery. All patients underwent foramen magnum decompression and duroplasty. Factors related to radiological success ( $\geq 50 \%$ decrease in the diameter of the syrinx) were investigated. The follow-up period was $72.7 \pm 55.6$ months.

Results : Preoperative functional status were MMS I in 11 patients and MMS II in 14 of CM type 1 and MMS I in 8 and II in 5 of CM type 1.5. Of patients with MMS II, 5/14 patients in group A and 3/5 patients in group B showed improvement and there was no case of deterioration. Radiological success was achieved in 32 (84\%) patients and restoration of the cisterna magna $(p=0.01 ; 0 \mathrm{R}, 46.5)$ was the only significant factor.

Conclusion : Migration of the medulla oblongata did not make a difference in the surgical outcome when the cisterna magna was restored.

Key Words : Chiari malformation · Hindbrain · Medulla oblongata $\cdot$ Surgery $\cdot$ Syringomyelia $\cdot$ Arachnoid.

\section{INTRODUCTION}

Chiari malformation (CM) is characterized by ectopia of the hindbrain through the foramen magnum ${ }^{12,16)}$. Typically, tonsillar descent of $>5 \mathrm{~mm}$ is defined as CM type 1 . Although the exact pathophysiology has not been determined, disturbance of free cerebrospinal fluid (CSF) flow at the craniocervical junction is a common component of several theories, ${ }^{6,11,12,21)}$. Treatment is indicated for symptomatic patients, particularly when CM is combined with syringomyelia in adult patients ${ }^{8,18)}$. The surgical results are variable, with rates of success ranging from $80-100 \%{ }^{2,3,5,10,15)}$. The cause of CM may be idiopathic or secondary. There are many secondary causes of CM, such as hydrocephalus, congenital vertebral anomaly and arachnoid scarring, and these factors may contribute to the variation in outcomes ${ }^{2,3,10,15)}$. In the case of idiopathic CM type 1, restoration of the cisterna magna by foramen magnum decompression (FMD) and duroplasty seems to be a sufficient treatment for restoration of free CSF flow ${ }^{5}$. However, caudal migration of the medulla oblongata is present in certain patients with CM type 1 , and this condition is referred to as CM type 1.5 in pediatric patients ${ }^{22)}$. The surgical outcome is poorer in pediatric CM type 1.5 than in CM type $1^{22)}$. However, the significance of additional migration of the medulla oblongata in adult patients is unknown. We hypothesized that additional migration of the medulla oblongata would also be associated with disturbed CSF flow and that the surgical outcomes would not differ between adult CM type 1 and CM type 1.5 if normal CSF flow were restored. The objective of the present study was

- Received : April 4, 2016 • Revised : June 21, 2016 •Accepted : June 21, 2016

- Address for reprints : Chun Kee Chung, M.D., Ph.D.

Department of Neurosurgery, Seoul National University College of Medicine, 101 Daehak-ro, Jongno-gu, Seoul 03080, Korea

Tel : +82-2-2072-2352, Fax : +82-2-744-8459, E-mail : chungc@snu.ac.kr

- This is an Open Access article distributed under the terms of the Creative Commons Attribution Non-Commercial License (http://creativecommons.org/licenses/by-nc/3.0) which permits unrestricted non-commercial use, distribution, and reproduction in any medium, provided the original work is properly cited. 
to analyze surgical outcomes of adult idiopathic CM type 1 with and without additional migration of medulla oblongata.

\section{MATERIALS AND METHODS}

The cases of patients with CM type 1, who were surgically treated at an adult hospital from 1988-2012, were retrospectively reviewed. We included patients with syringomyelia, and excluded patients with possible secondary causes, such as a history of meningitis, encephalitis, hydrocephalus, intracranial lesions, an occipitocervical anomaly, brain or spine surgery, or head trauma. A total of 47 patients were identified. Of these patients, 38 (81\%) with traceable medical records and at least a 12-month follow-up period were included in the present study $(\mathrm{M}: \mathrm{F}=11$ : 27; mean age, $34.7 \pm 13.8$ years; median, 33.5 ; range, $18-63$ ). Preoperatively, all patients underwent whole-spine magnetic resonance (MR) imaging, and the mid-sagittal T1- and T2-weighted MR images were reviewed. Thirteen patients (34\%) had additional migration of the medulla oblongata, which was indicated when the obex was located below the foramen magnum ${ }^{7,22)}$. CM type 1 without herniation of the medulla oblongata was classified as Group A, and CM type 1 with herniation of the medulla oblongata was classified as Group B. Syringomyelia was confined to the cervical spinal cord in 2 patients and extended to the thoracic spinal cord in 36 patients. Both functional and clinical outcomes were reviewed. The modified McCormick scale (MMS) (Table 1) was used to evaluate functional status of the patients before surgery and one year after surgery ${ }^{17)}$. Clinically, the presenting symptoms/signs were varied, and each patient had a variable combination of symptoms/signs. Sensory disturbance in the upper limb(s) was the most common symptom, present in 24 patients, and lower-limb sensory disturbance was present in 9 patients. Upper-extremity weakness was also observed in 5 patients, and lower-extremity weakness was observed in 4 patients. Other symptoms included the following : neck pain, affecting 13 patients; headache, 4 ; and dizziness, 1 . The patients were encouraged to ambulate from the day of surgery and walked home at approximately postoperative day 7 . The patients were scheduled to visit the outpatient clinic at 3, 6 and 12 months postoperatively and yearly thereafter. Follow-up MR imaging was performed between postoperative 6 and 12 months and was repeated at 12-24 months if the size of the syringomyelia cavities had not

Table 1. Modified McCormick scale

\begin{tabular}{cc}
\hline Grade & \multicolumn{1}{c}{ Definition } \\
\hline I & $\begin{array}{c}\text { Neurologically intact, ambulate normally, may have minimal } \\
\text { dysethesia }\end{array}$ \\
II & $\begin{array}{c}\text { Mild motor and sensory deficit, maintain functional } \\
\text { independence }\end{array}$ \\
III & $\begin{array}{c}\text { Moderate deficit, limitation in function, independent with } \\
\text { external aid }\end{array}$ \\
IV & Severe motor or sensory deficit, depend on external assistance \\
V & Paraplegia or quadriplegia \\
\hline
\end{tabular}

decreased sufficiently in the prior image. Thereafter, MR imaging was performed according to the symptoms of the patients. The patients were followed up for $72.7 \pm 55.6$ months (median, 56.5 months; range, 12-232 months).

\section{Surgical procedures}

This study was retrospective, so the surgical procedures differed over time. Suboccipital craniotomy (FMD) and removal of the posterior $\mathrm{C} 1$ ring were performed in all patients. Additional removal of the C2 lamina was selectively performed if preoperative MR imaging demonstrated that the tip of the tonsil reached the C2 level. In the past, the arachnoid was opened frequently, and tonsillar resection was performed. More recently, the arachnoid was left intact if there was no arachnoid pathology and if free CSF flow was observed in the subtonsillar subarachnoid space. In patients with secondary causes, the arachnoid membrane was opened and tonsillectomy was performed, if necessary. Duroplasty was performed in all patients. The wound was closed layer by layer, without a closed-suction drain ${ }^{19)}$.

\section{Statistical analysis}

We analyzed factors affecting radiological success, rather than clinical success, because comparison of the diverse clinical symptoms was inconsistent ${ }^{10)}$. The ratio between the largest diameter of the spinal syrinx on each MR image and that of the spinal cord on preoperative MR imaging was used to evaluate the change in syringomyelia ${ }^{2)}$. Radiological success was defined as when the syrinx ratio decreased by more than $50 \%$ during the postoperative 12 months. Clinical (age, sex, motor symptoms, duration of symptoms, and MMS), radiological [the extent of the syrinx (cervical vs. cervicothoracic), sufficient postoperative restoration of the cisterna magna, and migration of the medulla oblongata (Group A vs. Group B)] and surgical (arachnoid dissection, tonsillectomy, and syrinx-subarachnoid shunting) factors were included in the risk factors analysis. The cut-off value for continuous variables was determined by ROC curve analysis. Restoration of the cisterna magna was regarded as sufficient when the length of the dorsal CSF pathway was $\geq 12.0 \mathrm{~mm}$ at the level of the foramen magnum in mid-sagittal T2-weighted MR images collected at postoperative 6-12 months ${ }^{5}$. All statistical analyses were performed using the commercially available software SPSS, version 17.0 (SPSS Inc., Chicago, IL, USA). Non-parametric continuous values were compared using Mann-Whitney's U test or the Wilcoxon rank sum test, and dichotomous values were analyzed with the chi-square test. Two-sided $p$-values $<0.05$ were considered statistically significant. We certify that all applicable institutional and governmental regulations concerning the ethical use of human volunteers/animals were followed during the course of this research.

\section{RESULTS}

There were no differences in patient demographics between 
groups (Table 2). Tonsillar beaking (pointing) was present in all patients. The extent of tonsillar descent was greater in Group B

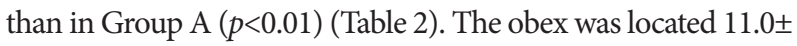
$4.7 \mathrm{~mm}$ (range, 4.3-19) below the foramen magnum in Group B. Syringomyelia was decreased by more than $50 \%$ in $32(84 \%)$ patients (21/25 in group A and 11/13 in group B). The preoperative syrinx ratio was $0.75 \pm 0.23$, which decreased to $0.20 \pm 0.18$ at the last follow-up $(p<0.05)$. The extent of the decrease did not differ between Group A (75.3 $\pm 20.3 \%)$ and Group B (68.1 $\pm 27.4 \%)$ $(p=0.60)$. An analysis of factors related to radiological improvement revealed that sufficient restoration of the cisterna magna ( $p=0.01$; OR, 46.5; 95\% CI, 3.2-676.2) was the only significant factor (Table 3). Preoperative functional status were MMS I in 11 patients and MMS II in 14 patients of group A and MMS I in 8 and MMS II in 5 patients of group B. Postoperatively, clinical symptoms were improved in 31 (82\%) patients $(21 / 25$ in

Table 2. The characteristics of patients

\begin{tabular}{lccr}
\hline & $\begin{array}{c}\text { Group A } \\
(\mathrm{n}=25)^{*}\end{array}$ & $\begin{array}{c}\text { Group B } \\
(\mathrm{n}=13)\end{array}$ & \\
\hline Age (years, mean \pm SD) & $34.2 \pm 15.3$ & $31.8 \pm 11.8$ & 0.93 \\
Sex $(\mathrm{M}: \mathrm{F})$ & $10: 15$ & $1: 12$ & 0.06 \\
Duration of symptom (month) & $37.4 \pm 41.5$ & $41.3 \pm 55.7$ & 0.63 \\
Motor symptom (yes) & 4 patients & 1 patient & 0.64 \\
Syrinx ratio & $0.79 \pm 0.20$ & $0.70 \pm 0.27$ & 0.71 \\
Tonsil descent $(\mathrm{mm})$ & $7.02 \pm 1.78$ & $14.40 \pm 6.08$ & $<0.01$ \\
Obex descent $(\mathrm{mm})$ & 0 & $11.0 \pm 4.7$ & \\
\hline
\end{tabular}

All of the continuous variables are presented as the mean \pm standard deviation. ${ }^{*}$ Chiari malformation type 1 without herniation of medulla oblongata was classified as group $\mathrm{A}$ and Chiari malformation type 1 with herniation of medulla oblongata was Group B

Table 3. The prognostic factor for the reduction of syringomyelia more than $50 \%$

\begin{tabular}{|c|c|c|}
\hline & Factors & $p$-value \\
\hline \multirow{4}{*}{ Clinical } & Age $^{\star}$ (cut-off, $\geq 23$ years) & 0.65 \\
\hline & Sex & 0.65 \\
\hline & Motor symptom & 1.00 \\
\hline & $\begin{array}{l}\text { Duration of symptom } \\
\quad \text { (cut-off, } \geq 3.5 \text { month) }\end{array}$ & 0.40 \\
\hline Group $^{\ddagger}$ & A vs. B & 0.96 \\
\hline Radiological & $\begin{array}{l}\text { Extent of syrinx } \\
\text { (cervical vs. cervico-thoracic) }\end{array}$ & 1.00 \\
\hline \multirow[t]{6}{*}{ Surgical } & Duraplasty & 1.00 \\
\hline & Arachnoid dissection & 1.00 \\
\hline & Arachnoid inflammation & 1.00 \\
\hline & Tonsilectomy & 1.00 \\
\hline & Syringosubarachnoid shunt & 1.00 \\
\hline & Cisterna magna restoration & $\begin{array}{c}0.005(\mathrm{OR}, 46.5 \\
95 \% \mathrm{CI}, 3.2-676.2)\end{array}$ \\
\hline \multicolumn{3}{|c|}{$\begin{array}{l}{ }^{*} \text { Cut-off value was determined with ROC curve : sensitivity } 66 \% \text { and specificity } \\
50 \%,{ }^{\dagger} \text { Cut-off value was determined with ROC curve : sensitivity } 44 \% \text { and speci- } \\
\text { ficity } 43 \% \text {, }{ }^{\ddagger} \text { Chiari malformation type } 1 \text { without herniation of medulla oblongata } \\
\text { was classified as group A and Chiari malformation type } 1 \text { with herniation of me- } \\
\text { dulla oblongata was Group B. Cl : confidence interval, ROC : receiver operating } \\
\text { characteristic }\end{array}$} \\
\hline
\end{tabular}

group A and 10/13 in group B). Of patients with MMS II, 8 patients showed functional improvement (5/14 in group A and $3 / 5$ in group B), from MMS II to I, and there was no case of deterioration from MMS I and II (Table 4). Although clinical improvement was noted, minimal change of clinical symptoms was not reflected in MMS. Complications occurred in 2 patients in Group A (cerebellar contusion in 1 and subdural hemorrhage in 1) and 3 patients in Group B (CSF leakage in 2 and epidural hemorrhage in 1). Reoperation was necessary in 2 patients due to epidural hemorrhage and subdural hemorrhage. During the follow-up period, no case required reoperation.

\section{Surgical procedures}

The numbers of patients who underwent each surgical procedure are given in Fig. 1. Intraoperative findings showed that the arachnoid was clear in all patients and was left intact in $11 / 25$ patients in Group A and 5/13 patients in Group B ( $p=0.74)$. Before December 2005, arachnoid dissection and/or tonsillectomy were performed in 15/17 patients, and they were performed in 7/21 patients after January 2006. A syringo-subarachnoid shunt was inserted in 3/4 patients before 1991 .

\section{Case illustrations}

The following two cases exemplify dynamic changes in hindbrain herniation in response to surgical treatment.

Table 4. Functional status of patients before and 1 year after surgery

\begin{tabular}{|c|c|c|c|c|c|c|}
\hline \multirow{2}{*}{ Initial MMS } & \multicolumn{6}{|c|}{ Postop 1 yr MMS } \\
\hline & I & II & III & IV & $\mathrm{V}$ & Total \\
\hline \multicolumn{7}{|l|}{ Total $(n=38)$} \\
\hline $\mathrm{I}$ & 19 & 0 & 0 & 0 & 0 & 19 \\
\hline II & 8 & 10 & 1 & 0 & 0 & 19 \\
\hline III & 0 & 0 & 0 & 0 & 0 & 0 \\
\hline IV & 0 & 0 & 0 & 0 & 0 & 0 \\
\hline $\mathrm{V}$ & 0 & 0 & 0 & 0 & 0 & 0 \\
\hline Total & 27 & 10 & 1 & 0 & 0 & 38 \\
\hline \multicolumn{7}{|l|}{ Group A $(n=25)$} \\
\hline I & 11 & 0 & 0 & 0 & 0 & 11 \\
\hline II & 5 & 9 & 0 & 0 & 0 & 14 \\
\hline III & 0 & 0 & 0 & 0 & 0 & 0 \\
\hline IV & 0 & 0 & 0 & 0 & 0 & 0 \\
\hline $\mathrm{V}$ & 0 & 0 & 0 & 0 & 0 & 0 \\
\hline Total & 16 & 9 & 0 & 0 & 0 & 25 \\
\hline \multicolumn{7}{|l|}{ Group B $(n=13)$} \\
\hline I & 8 & 0 & 0 & 0 & 0 & 8 \\
\hline II & 3 & 2 & 0 & 0 & 0 & 5 \\
\hline III & 0 & 0 & 0 & 0 & 0 & 0 \\
\hline IV & 0 & 0 & 0 & 0 & 0 & 0 \\
\hline $\mathrm{V}$ & 0 & 0 & 0 & 0 & 0 & 0 \\
\hline Total & 11 & 2 & 0 & 0 & 0 & 13 \\
\hline
\end{tabular}

MMS : modified McCormick scale, postop : postoperative, yr : year 


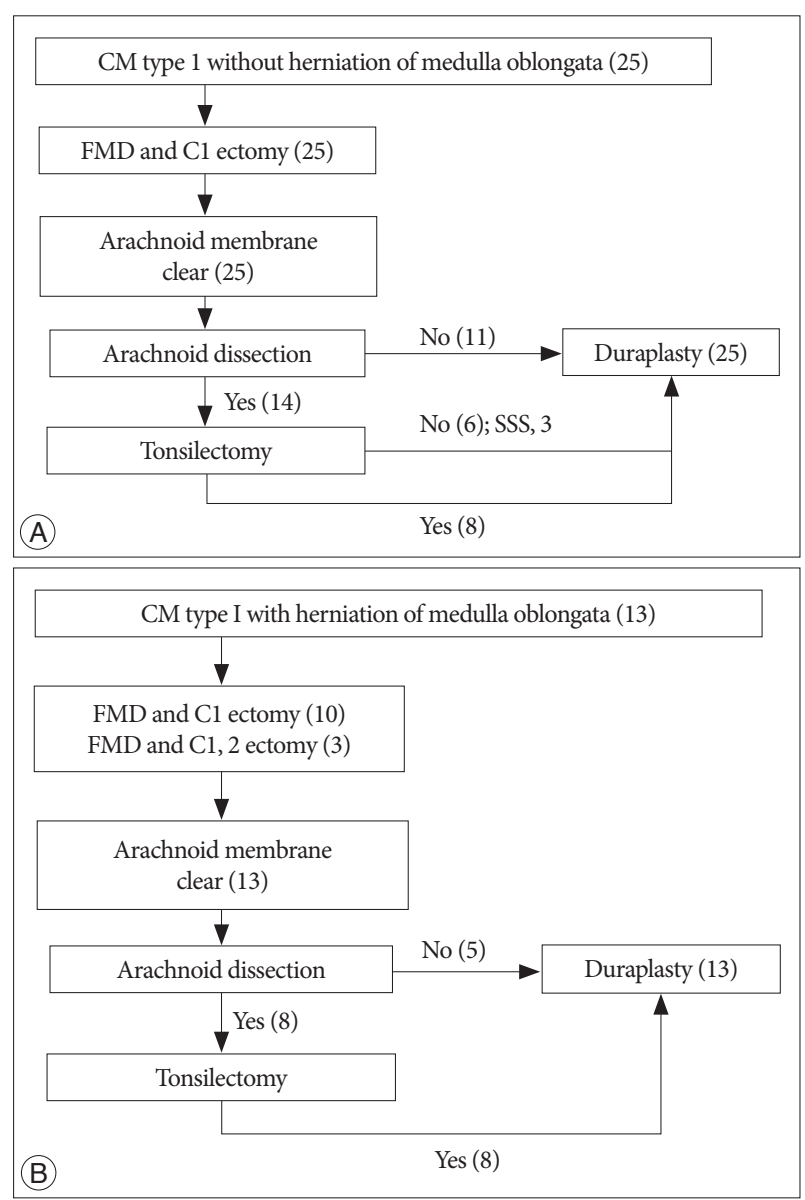

Fig. 1. The algorithm of the surgical procedures. The surgical procedures for Chiari malformation (CM) type 1 without herniation of the medulla oblongata (A). The numbers in parentheses represent the numbers of patients. Similarly, the surgical procedures for Chiari malformation type 1 with herniation of the medulla oblongata (B). FMD : foramen magnum decompression, C1 ectomy : removal of the posterior C1 ring, C2 ectomy : partial or total laminectomy of C2, SSS : syringo-subarachnoid shunt.

\section{Case 1}

A 21-year-old man presented with a 5-month history of decreased sensation in his right leg. MR imaging showed a CM type I and migration of the medullar oblongata with large syrinx on the cervical spine. The obex and tonsil were located 16.1 $\mathrm{mm}$ and $17.2 \mathrm{~mm}$, respectively, below the foramen magnum (Fig. 2A). CM type 1 with syringomyelia was diagnosed, and $\mathrm{FMD}$, removal of the posterior $\mathrm{C} 1$ ring and duroplasty were performed. The arachnoid membrane was left intact because it was clear, and free CSF flow was observed in the subtonsillar subarachnoid space. MR imaging performed 2 days after surgery showed similar hindbrain herniation and syringomyelia (Fig. 2B). His sensation was normalized from postoperative 3 months, and MR imaging performed at 6 months showed a marked improvement in the syringomyelia and normalization of the hindbrain herniation. The size of the dorsal CSF pathway was $14.5 \mathrm{~mm}$, and rounding of the tonsil was also observed (Fig. 2C). The syrinx had nearly disappeared at postoperative month 24 .

\section{Case 2}

A 20-year-old female presented with a 7.5-year history of decreased sensation in her right upper extremity. MR imaging showed CM type 1, additional migration of the medulla oblongata and syringomyelia (Fig. 3A). The tonsil and obex were located $6.5 \mathrm{~mm}$ and $5.7 \mathrm{~mm}$, respectively, below the foramen magnum. $\mathrm{FMD}$ and removal of the posterior $\mathrm{C} 1$ ring were performed. $\mathrm{Al}-$ though the arachnoid membrane was clear, arachnoid dissection, tonsilectomy and duroplasty were performed. MR imaging performed 3 months after the operation did not show rounding of the tonsil, restoration of the cisterna magna or improvement in the syringomyelia (Fig. 3B). The obex was located $5.1 \mathrm{~mm}$ below the foramen magnum. The herniation of the medulla oblongata progressed with time, and the locations of the obex at 9 , 15 , and 27 months were 7.2, 8.2, and $12.1 \mathrm{~mm}$, respectively. Her symptoms were not improved. MR imaging performed at 50 months showed further herniation of the tonsil $(13 \mathrm{~mm})$ and medulla oblongata (obex, $12.9 \mathrm{~mm}$ below the foramen magnum) (Fig. 3C), which was more severe than that observed in the preoperative images. The patient refused reoperation because her symptoms were stationary and similar to her preoperative state.

\section{DISCUSSION}

The objective of the present study was to analyze prognostic factors. Herniation of the medulla oblongata was observed in $34 \%$ (13/38) of patients in the present study. Syringomyelia and clinical symptoms were improved in 32 (84\%) and 31 (82\%) patients, respectively. The sufficient restoration of the cisterna magna $(p=0.01)$ was the only significant factor. The reduction in syringomyelia after restoration of the cisterna magna was not dependent on herniation of the medulla oblongata $(p=0.96)$. We demonstrated that hindbrain herniation changes dynamically, depending on whether successful restoration of the cisterna magna is achieved in Case 1 and 2.

\section{Chiari malformation type $\mathbf{1 . 5}$}

CM type 1.5 is defined as a combination of brain stem herniation through the foramen magnum in addition to the presence of CM type 1 in pediatric patients ${ }^{22)}$. The obex has been found to lie $14 \pm 4 \mathrm{~mm}$ below the foramen magnum $(11.0 \pm 4.7 \mathrm{~mm}$ in the present study ${ }^{22)}$. In pediatric patients, the incidence is $17 \%{ }^{23)}$. Although no differences in clinical symptoms or the incidence of syringomyelia are characteristic of CM type $1.5^{21,22)}$, persistent syringomyelia after posterior decompressive surgery and duroplasty has been reported to be twofold higher in CM type 1.5 than in CM type 1 (14\% vs. $7 \%$ ), and elective resection of the tonsil has been recommended ${ }^{22}$. Kim et al. ${ }^{7)}$ reported a case of spontaneous progression of pediatric CM type 1 to CM type 1.5 over a 9-year follow-up. The incidence and significance of medulla oblongata herniation in adult idiopathic CM type 1 have not been reported.

In the present study, dynamic changes in hindbrain hernia- 

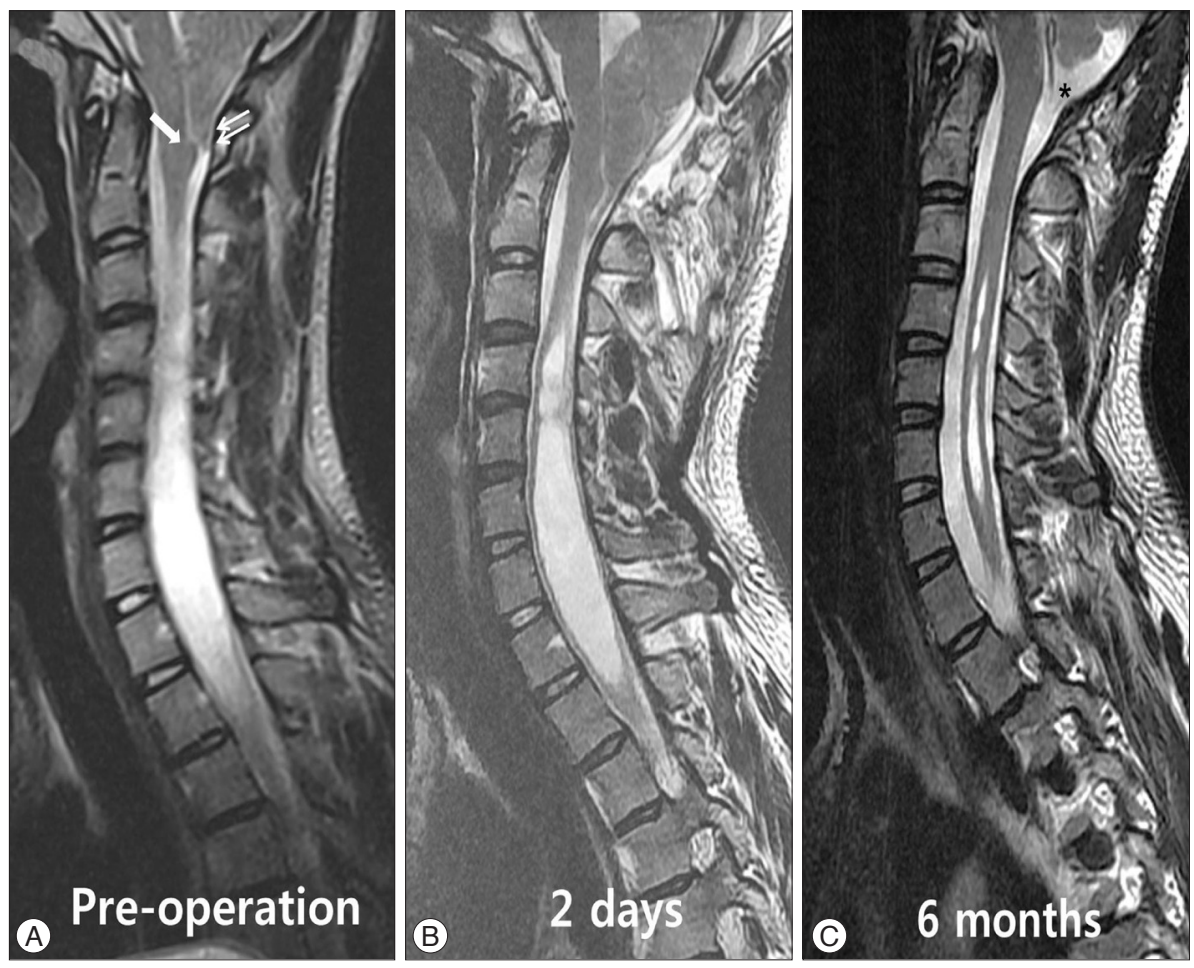

Fig. 2. Normalization of hindbrain herniation after restoration of the cisterna magna. The T2-weighted sagittal magnetic resonance (MR) image shows syringomyelia in the whole spine. The obex (arrow) and tonsil (double arrow) are located $16.1 \mathrm{~mm}$ and $17.2 \mathrm{~mm}$, respectively, below the foramen magnum (A). Tonsillar beaking is observed. Postoperative day 2 : the syringomyelia is slightly reduced, but the retrocerebellar and subtonsillar subarachnoid spaces are not markedly changed (B). Postoperative month 6 : the syringomyelia is reduced by more than $50 \%$, and restoration of the cisterna magna $\left(^{*}\right)$ is prominent (C). The length of the dorsal cerebrospinal fluid pathway is $14.5 \mathrm{~mm}$. The tonsil and obex are located above the foramen magnum, and rounding of the tonsil is present.
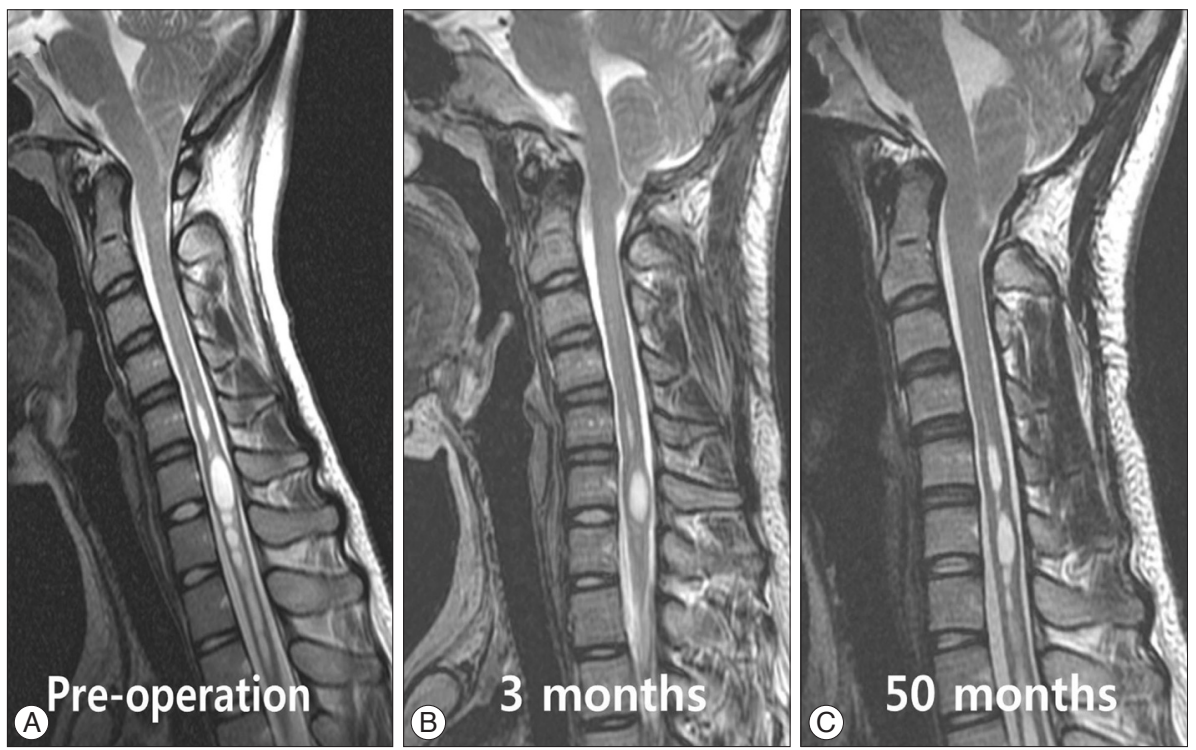

Fig. 3. Aggravation of hindbrain herniation after failed restoration of the cisterna magna. The T2-weighted sagittal magnetic resonance (MR) image shows syringomyelia in the cervical and thoracic spine. The tonsil and obex are located $6.5 \mathrm{~mm}$ and $5.7 \mathrm{~mm}$, respectively, below the foramen magnum (A). Tonsillar beaking is also present. Postoperative month 3 : the syringomyelia and hindbrain herniation are similar (B). The cisterna magna is not reconstructed. Postoperative month 50 : the obex lies $12.9 \mathrm{~mm}$ below the foramen magnum, with persistent syringomyelia (C).

tion were illustrated in Cases 1 and 2. Although it was not specified, we found similar findings in other papers ${ }^{5,7,9)}$. In those studies, the surgical strategy was not influenced by additional herniation of the medulla oblongata ${ }^{5,79)}$. If there were no arachnoid pathology, rapid CSF flow through the narrow subarachnoid space resulted in a pressure difference between the cranial and the caudal compartments (the Venturi effect), which caused hindbrain herniation, and further migration of the medulla oblongata could occur over time ${ }^{4)}$. These findings suggest that the adverse consequences could be resolved by eliminating the Venturi effect itself ${ }^{14}$. Therefore, the goal of surgery is the restoration of unimpeded flow of the CSF across the craniocervical junction by enlarging the retrocerebellar and subtonsillar cisterns (restoration of the cisterna magna), allowing the normal CSF pulsations to be transmitted into the spinal subarachnoid space ${ }^{2,3,13,18,20)}$.

\section{Surgical treatment}

The value of opening the arachnoid membrane and performing tonsillectomy to restore the cisterna magna is questionable. Many papers have supported arachnoid opening and/or tonsillectomy ${ }^{1-3,10)}$. However, a successful surgical outcome (100\% normalization of hindbrain herniation) was reported without arach- 
noid opening by Heiss et al. ${ }^{5)}$. Klekamp ${ }^{10)}$ showed that combined arachnoid pathology was a strong risk factor for symptom recurrence $(O R, 7.4)$ in a large case series $(n=371)$. The arachnoid membrane was normal only in 59/371 patients, and neurological deterioration was observed in $13 \%$ of cases within 5 years and in $19 \%$ within 10 years after the surgery. ${ }^{10)}$ In contrast, Alfieri and Pinna ${ }^{1)}$ reported that recurrence was observed in only $1.8 \%(2 / 109)$ of patients over a median of 12.7 years in a study that included only patients without arachnoid pathology. These results imply that arachnoid pathology might cause an unpredictable surgical outcome, most likely due to different pathophysiology. In the present study, patients with possible arachnoid pathology were excluded. The only significant prognostic factor was sufficient restoration of the cisterna magna; arachnoid opening and tonsillectomy were not significant factors. For patients without arachnoid pathology, adequate restoration of the cisterna magna with FMD, decompression of C1/C2 and duroplasty may be sufficient, even for patients with additional herniation of the medulla oblongata. Although the definition of "adequate" is not established, confirming free CSF flow in the subtonsillar subarachnoid space during the operation may lead to adequate cisterna magna restoration ${ }^{1,2,4,5)}$.

\section{Limitations}

First, the present study was a retrospective analysis of $38 \mathrm{pa}-$ tients and the small number may have resulted in a lower statistical power. Second, the surgical procedure was not uniform, and selection of the surgical procedure evolved over time. A prospective randomized controlled trial with long-term follow-up will be essential to establish the practical value of each surgical procedure. Third, the follow-up period ( $72.7 \pm 55.6$ months; median, 56.5 months; range, $12-232$ months) was not sufficient to draw a solid conclusion.

\section{CONCLUSION}

Normalization of CSF flow was the most important surgical goal for adult patients with idiopathic CM type 1. Migration of the medulla oblongata did not make a difference in the surgical outcome when the cisterna magna was restored. A long-term follow-up study with a large number of patients will be necessary to confirm these findings.

\section{- Acknowledgements}

This research was supported by Basic Science Research Program through the National Research Foundation of Korea (NRF) funded by the Ministry of Science, ICT and future Planning (2014R1A2A1A11049662).

This study was approved by the Institutional Review Board of the Clinical Research Institute at Seoul National University Hospital (IRB no. 1306004-491).

\section{References}

1. Alfieri A, Pinna G : Long-term results after posterior fossa decompres- sion in syringomyelia with adult Chiari Type I malformation. J Neurosurg Spine 17 : 381-387, 2012

2. Bao C, Yang F, Liu L, Wang B, Li D, Gu Y, et al. : Surgical treatment of Chiari I malformation complicated with syringomyelia. Exp Ther Med $5: 333-337,2013$

3. Batzdorf U, McArthur DL, Bentson JR : Surgical treatment of Chiari malformation with and without syringomyelia : experience with 177 adult patients. J Neurosurg 118 : 232-242, 2013

4. Greitz D : Unraveling the riddle of syringomyelia. Neurosurg Rev 29 : 251-263; discussion 264, 2006

5. Heiss JD, Suffredini G, Bakhtian KD, Sarntinoranont M, Oldfield EH : Normalization of hindbrain morphology after decompression of Chiari malformation Type I. J Neurosurg 117 : 942-946, 2012

6. Kalb S, Perez-Orribo L, Mahan M, Theodore N, Nakaji P, Bristol RE : Evaluation of operative procedures for symptomatic outcome after decompression surgery for Chiari type I malformation. J Clin Neurosci 19 : 1268-1272, 2012

7. Kim IK, Wang KC, Kim IO, Cho BK : Chiari 1.5 malformation : an advanced form of Chiari I malformation. J Korean Neurosurg Soc 48 : 375-379, 2010

8. Kim J, Kim CH, Jahng TA, Chung CK : Clinical course of incidental syringomyelia without predisposing pathologies. J Clin Neurosci 19 : 665668,2012

9. Klekamp J : Neurological deterioration after foramen magnum decompression for Chiari malformation type I : old or new pathology? J Neurosurg Pediatr 10 : 538-547, 2012

10. Klekamp J : Surgical treatment of Chiari I malformation--analysis of intraoperative findings, complications, and outcome for 371 foramen magnum decompressions. Neurosurgery $71: 365$-380; discussion 380, 2012

11. Klekamp J : The pathophysiology of syringomyelia - historical overview and current concept. Acta Neurochir (Wien) 144 : 649-664, 2002

12. Koyanagi I, Houkin K : Pathogenesis of syringomyelia associated with Chiari type 1 malformation : review of evidences and proposal of a new hypothesis. Neurosurg Rev 33 : 271-284; discussion 284-285, 2010

13. Lee JH, Chung CK, Kim HJ : Cerebral dissection from syringomyelia demonstrated using cine magnetic resonance imaging. Case report. J Neurosurg 94 : 318-321, 2001

14. Lee JH, Chung CK, Kim HJ : Decompression of the spinal subarachnoid space as a solution for syringomyelia without Chiari malformation. Spinal Cord 40 : 501-506, 2002

15. Logue V, Edwards MR : Syringomyelia and its surgical treatment--an analysis of 75 patients. J Neurol Neurosurg Psychiatry 44 : 273-284, 1981

16. Loukas M, Noordeh N, Shoja MM, Pugh J, Oakes WJ, Tubbs RS : Hans Chiari (1851-1916). Childs Nerv Syst 24 : 407-409, 2008

17. McCormick PC, Torres R, Post KD, Stein BM : Intramedullary ependymoma of the spinal cord. J Neurosurg $72: 523-532,1990$

18. Shamji MF, Ventureyra EC, Baronia B, Nzau M, Vassilyadi M : Classification of symptomatic Chiari I malformation to guide surgical strategy. Can J Neurol Sci 37 : 482-487, 2010

19. Sohn S, Chung CK, Kim CH : Is closed-suction drainage necessary after intradural primary spinal cord tumor surgery? Eur Spine J 22 : 577-583, 2013

20. Song SW, Chung CK : Acquired Chiari malformation. J Korean Neurosurg Soc $40: 38-39,2006$

21. Tubbs RS, Beckman J, Naftel RP, Chern JJ, Wellons JC 3rd, Rozzelle CJ, et al. : Institutional experience with 500 cases of surgically treated pediatric Chiari malformation Type I. J Neurosurg Pediatr 7 : 248-256, 2011

22. Tubbs RS, Iskandar BJ, Bartolucci AA, Oakes WJ : A critical analysis of the Chiari 1.5 malformation. J Neurosurg 101 (2 Suppl) : 179-183, 2004

23. Tubbs RS, McGirt MJ, Oakes WJ : Surgical experience in 130 pediatric patients with Chiari I malformations. J Neurosurg 99 : 291-296, 2003 